\title{
Recent advances in therapies for the eating disorders Glenn Waller
}

Address: Glenn Waller, Vincent Square Clinic, Osbert Street, London SW1P 2QU, UK

Email: glenn.waller@iop.kcl.ac.uk

FI000 Medicine Reports 2009, I:38 (doi:10.3410/MI-38)

The electronic version of this article is the complete one and can be found at: http://FI000.com/Reports/Medicine/content/I/38

\begin{abstract}
In the first part of this decade, many reviews of the impact of treatments for the eating disorders were conducted, with broadly similar conclusions. This review provides an update on progress (or otherwise) in the field over the past three years.
\end{abstract}

\section{Introduction and context}

The eating disorders have proven a challenge for clinicians since they were first identified. Such patients often have physical safety needs as a priority, and then require effective therapy for the eating disorder itself. This review focuses on recent developments in the latter part of that process - treatment for the eating pathology. Many authoritative treatment reviews have been published in recent years [1-7], based on synthesis of both the empirical evidence and expert clinical experience. They include recommendations for both physical safety and therapies, and have been relatively consistent in their conclusions. Their key empirical findings regarding therapies for the eating disorders are as follows.

\section{For adult sufferers}

1. Psychological treatments have relatively low levels of impact on anorexia nervosa, and there is no clear difference in outcome between such treatments.

2. Physical treatments for anorexia nervosa (for example, nutrition or medication) are needed to ensure safety (for example, biological safety or psychiatric risk), but there is no consistent evidence that those treatments have an impact on the anorexia nervosa itself.

3. Psychological treatments for bulimia nervosa and binge eating disorder are relatively effective, with strong evidence for the impact of cognitive behavioural therapy (CBT) and interpersonal psychotherapy (the former being faster to take effect than the latter).
4. Antidepressants (particularly fluoxetine) are effective in reducing the level of bulimic symptoms in bulimia nervosa and binge eating disorder, though the duration of the effect may be short-term.

5. Self-help approaches have a relatively low level of impact on the eating disorders, producing little impact on abstinence from behaviours [8].

6. Apart from binge eating disorder, there is little evidence of the impact of treatment for atypical cases (which probably represent the largest number of sufferers [5]).

\section{For younger sufferers}

1. There is no clear evidence regarding what works for children.

2. Adolescents with anorexia nervosa benefit more from family-orientated therapies than individual therapies, though there is little evidence for such a difference in bulimic or atypical cases.

Of course, these conclusions should be read alongside the expert clinical opinions that the guidelines use to supplement the evidence base (particularly where there is no real empirical base to rely on).

\section{Recent advances}

The past 3 years have yielded significant advances in our knowledge base that are not reflected in these reviews. Some of those advances are in the form of consolidation 
of the existing positive evidence, some are new conclusions, and some are disappointingly negative findings. One key finding is that relatively few patients who are referred to specialist services either make it through to treatment or complete that treatment [9]. This finding needs to be taken into account when considering the following advances.

\section{Types of therapy}

Motivational enhancement

A number of motivational approaches have been trialled as adjuncts to other therapeutic methods. The recent evidence from this work is mixed, with motivational enhancement therapy proving relatively ineffective for inpatients with eating disorders (leading to little reliable change in motivation or in eating pathology itself) [10]. There is some evidence of increased motivational benefit among binge eaters, though there is less consistency regarding change in their eating pathology $[11,12]$.

Cognitive behavioural therapy

Among bulimic cases, CBT has extended its evidence base considerably [13]. That development parallels improvements in this form of therapy [14,15], although whether CBT is actually applied in broad clinical practice is questionable [16]. It has been shown that CBT can be individualised and applied to patients in non-research settings [17]. The most important finding is an improved outcome with bulimic cases (and comparable outcomes with atypical cases - see below) [18]. There is preliminary evidence that relatively complex cases benefit most from a more complex form of CBT [18] and that some in-patients can benefit from a CBT-based programme [19]. However, CBT remains unproven with relatively low-weight anorexic patients, where physical needs and starvation effects predominate.

\section{Dialectical behaviour therapy}

Dialectical behaviour therapy (DBT) has previously been proposed for use with bulimia and binge eating disorder. This stance has been supported by recent work using a version of DBT that is only minimally adapted from the original [20].

\section{Medication}

There has been some advance in the field of psychopharmacology for bulimic eating disorders over the past few years, though these findings need replication and extension. First, there is some evidence that fluoxetine is useful for bulimic adolescents [21]. Second, sibutramine may be effective in the treatment of binge eating disorder [22]. Finally, topirimate seems to be effective in the short term for bulimic disorders where there is comorbid obesity [23].
There is no clear evidence for medication in the treatment of the core symptoms of anorexia nervosa, regardless of age $[21,24]$. There have been some suggestions that olanzapine might be a useful adjunct to other treatments for anorexia nervosa (particularly given its tendency to promote weight gain). However, it is too early to support this contention, given the differing outcomes of recent studies, their methodological weaknesses, and the lack of clarity about the mechanisms that might be involved [25-27].

\section{Specific subgroups of eating disordered patients Atypical cases}

As already identified, atypical cases constitute a very large proportion of the eating disordered population [5], but there has been almost no evidence on their treatment (beyond the subgroup of binge eating disorder patients). This gap has been addressed recently in adults and adolescents. Such cases can be successfully treated using similar methods to those employed with bulimic disorders, with broadly comparable outcomes $[17,18,28]$.

\section{Younger cases}

Family-oriented therapies still have a pre-eminent position with adolescents with anorexia nervosa [29]. However, there is now good evidence that both family and CBT approaches are effective for bulimia nervosa in adolescents [30].

\section{Methods of delivery \\ Self-help}

Recent findings in this domain have been uninspiring. A recent review has concluded that self-help for bulimia nervosa and binge eating disorder is beneficial, but only relative to a waiting list control condition. There is little evidence that this approach is more helpful than any active control condition [31].

\section{Electronic delivery}

Various researchers have tested electronic methods (for example, via internet, text messages, and CD-ROM) of delivering treatments that are effective when delivered individually. Unfortunately, the results are relatively weak and uptake is poor, leading to the conclusion that this is not yet a method of conducting therapy that can be widely recommended $[32,33]$.

\section{Implications for clinical practice}

In brief, recent findings reiterate and extend the role of CBT as the first line treatment for most adult cases of eating disorders (provided the CBT is delivered appropriately), extending its utility to younger cases and to atypical cases, and showing its effectiveness in 
non-research settings. However, existing self-help methods and the use of electronic media for delivery of CBT are not supported at present. The role of family therapy for younger cases is also more widely supported. There are more positive findings regarding the use of DBT and medication for bulimic disorders, but medication is not indicated for the core pathology of anorexia nervosa.

\section{Future directions in clinical research in therapies for the eating disorders}

Over the next few years, it will be important to monitor the following aspects of the treatment literature in the eating disorders:

1. Continued developments of psychological therapies for bulimic disorders and atypical eating disorders (for example, CBT, DBT), to enhance existing outcomes and to carry these effects further into everyday clinical practice.

2. Treatment outcomes for anorexia nervosa, including psychological and psychopharmacological approaches (findings are anticipated from a number of current trials).

3. The development of psychopharmacological approaches that relate to the psychobiology of the eating disorders (including anxiety structures) [34] that have more extensive periods of follow-up.

4. Psychological therapies that have been proposed to be valuable but where the evidence base is minimal should be tested more fully in order to demonstrate whether or not they meet the criteria for evidence-based practice.

5. The matching of psychological therapies to individuals, to ensure that individuals are offered the most effective treatment for their individual problem [18].

6. Working via carers, addressing both their own stress and making them more able to work as members of the broader team treating the sufferer [35].

7. The determination of whether treatment effects generalise across settings (for example, do therapies for restrictive problems tested in outpatient settings work as well in day- and in-patient settings?).

\section{Abbreviations}

CBT, cognitive behavioural therapy; DBT, dialectical behaviour therapy.

\section{Competing interests}

The author declares that he has no competing interests.

\section{Acknowledgements}

The author would like to thank Victoria Mountford for her helpful comments on this review.

\section{References}

I. Berkman ND, Lohr KN, Bulik CM: Outcomes of eating disorders: a systematic review of the literature. Int J Eat Disord 2007, 40:293-309.

2. Beumont $P$, Hay $P$, Beumont $D$, Birmingham $L$, Derham $H$, Jordan $A$, Kohn M, McDermott B, Marks P, Mitchell J, Paxton S, Surgenor L, Thornton C, Wakefield A, Weigall S; Royal Australian and New Zealand College of Psychiatrists Clinical Practice Guidelines Team for Anorexia Nervosa: Australian and New Zealand clinical practice guidelines for the treatment of anorexia nervosa. Aust N Z J Psychiatry 2004, 38:659-70.

3. Brownley KA, Berkman ND, Sedway JA, Lohr KN, Bulik CM: Binge eating disorder treatment: $A$ systematic review of randomised controlled trials. Int J Eat Disord 2007, 40:337-48.

4. Bulik CM, Berkman ND, Brownley KA, Sedway JA, Lohr KN: Anorexia nervosa treatment: A systematic review of randomised controlled trials. Int J Eat Disord 2007, 40:310-20.

5. Fairburn CG, Harrison PJ: Eating disorders. Lancet 2003, 36 I:407-16.

6. National Institute for Clinical Excellence: Eating Disorders: Core Interventions in the Treatment and Management of Anorexia Nervosa, Bulimia Nervosa and Related Eating Disorders (Clinical Guideline 9). London, UK: National Collaborating Centre for Mental Health; 2004.

7. Shapiro JR, Berkman ND, Brownley KA, Sedway JA, Lohr KN, Bulik CM: Bulimia nervosa treatment: a systematic review of randomised controlled trials. Int J Eat Disord 2007, 40:32I-36.

8. Perkins SJ, Murphy R, Schmidt U, Williams C: Self-help and guided self-help for eating disorders. Cochrane Database Syst Rev 2006, 3: CD004191.

9. Waller G, Schmidt U, Treasure J, Murray K, Aleyna J, Emanuelli F, Crockett J, Yeomans $M$ : Problems across care pathways in specialist adult eating disorder services. Psychiatric Bulletin 2009, 33:26-9.

10. Dean HY, Touyz SW, Rieger E, Thornton CE: Group motivational enhancement therapy as an adjunct to inpatient treatment for eating disorders: a preliminary study. Eur Eat Disord Rev 2008, 16:256-7.

II. Dunn EC, Neighbors C, Larimer ME: Motivational enhancement therapy and self-help treatment for binge eaters. Psychol Addict Behav 2006, 20:44-52.

12. Cassin SE, von Ranson KM, Heng K, Brar J, Wojtowicz AE: Adapted motivational interviewing for women with binge eating disorder: a randomized controlled trial. Psychol Addict Behav 2008, 22:417-25.

13. Mitchell JE, Agras S, Wonderlich S: Treatment of bulimia nervosa: where are we and where are we going? Int J Eat Disord 2007, 40:95-101.

14. Fairburn CG: Cognitive Behavior Therapy and Eating Disorders. New York, NY: Guilford; 2008.

15. Waller G, Corstorphine E, Cordery H, Hinrichsen H, Lawson R, Mountford V, Russell K: Cognitive-behavioral Therapy for the Eating Disorders: a Comprehensive Treatment Guide. Cambridge, UK: Cambridge University Press; 2007.

16. Tobin DL, Banker JD, Weisberg L, Bowers W: I know what you did last summer (and it was not CBT): a factor analytic model of international psychotherapeutic practice in the eating disorders. Int J Eat Disord 2007, 40:754-7.

17. Ghaderi A: Does individualization matter? A randomized trial of standardized (focused) versus individualized (broad) cognitive behavior therapy for bulimia nervosa. Beh Res Ther 2006, 44:273-88.

18. Fairburn CG, Cooper Z, Doll HA, O'Connor ME, Bohn K, Hawker DM, Wales JA, Palmer RL: Transdiagnostic cognitive- 
behavioral therapy for patients with eating disorders: a twosite trial with 60-week follow-up. Am J Psychiatry 2009, 166:3 I I-9.

Changes Clinical Practice

FI000 Factor 4.8 Recommended

Evaluated by Glenn Waller 23 Dec 2008, Nicole Barbarich-Marsteller 18 Feb 2009

19. Bowers WA, Ansher LS: The effectiveness of cognitive behavioural therapy on changing eating disorder symptoms and psychopathology of $\mathbf{3 2}$ anorexia nervosa patients at hospital discharge and one year follow-up. Ann Clin Psychiatry 2008, 20:79-86.

FI000 Factor 3.0 Recommended

Evaluated by Glenn Waller 09 Apr 2009

20. Chen EY, Matthews L, Allen C, Kuo JR, Linehan MM: Dialectical behavior therapy for clients with binge-eating disorder or bulimia nervosa and borderline personality disorder. Int J Eat Disord 2008, 41:505-12.

FI000 Factor 6.0 Must Read

Evaluated by Glenn Waller II Sep 2008

2I. Couturier J, Lock J: A review of medication use for children and adolescents with eating disorders. J Can Acad Child Adolesc Psychiatry 2007, I 6: I 73-6.

22. Wilfley DE, Crow SJ, Hudson JI, Mitchell JE, Berkowitz RI, Blakesley V, Walsh BT; Sibutramine Binge Eating Disorder Research Group: Efficacy of sibutramine for the treatment of binge eating disorder: a randomized multicenter placebo-controlled double-blind study. Am J Psychiatry 2008, I65:5I-8.

FI000 Factor 3.0 Recommended

Evaluated by Guido Frank 10 Jul 2008

23. Arbaizar B, Gómez-Acebo I, Llorca J: Efficacy of topiramate in bulimia nervosa and binge-eating disorder: a systematic review. Gen Hosp Psychiatry 2008, 30:47I-5.

24. Crow SJ, Mitchell JE, Roerig JD, Steffen K: What potential role is there for medication treatment in anorexia nervosa? Int J Eat Disord 2009, 42: I-8.

FI000 Factor 6.4 Must Read

Evaluated by Glenn Waller 24 Oct 2008, Daniel le Grange 10 Feb 2009

25. Bissada H, Tasca GA, Barber AM, Bradwejn J: Olanzapine in the treatment of low body weight and obsessive thinking in women with anorexia nervosa: a randomized, double-blind, placebo-controlled trial. Am J Psychiatry 2008, I65:|28|-8.

FI000 Factor 4.9 Must Read

Evaluated by Nicole Barbarich-Marsteller 15 Jul 2008, Guido Frank 18 Aug 2008, Beate Herpertz-Dahlmann 23 Jan 2009

26. Brambilla F, Garcia CS, Fassino S, Daga GA, Favaro A, Santonastaso P, Ramaciotti C, Bondi E, Mellado C, Borriello R, Monteleone P:
Olanzapine therapy in anorexia nervosa: psychobiological effects. Int Clin Psychopharmacol 2007, 22:197-204.

FI000 Factor 3.0 Recommended

Evaluated by Beate Herpertz-Dahlmann 07 Jan 2008

27. Halmi KA: The perplexities of conducting randomized, doubleblind, placebo-controlled treatment trials in anorexia nervosa patients. Am J Psychiatry 2008, 165:1227-8.

28. Schmidt U, Lee S, Perkins S, Eisler I, Treasure J, Beecham J, Berelowitz $M$, Dodge L, Frost S, Jenkins $M$, Johnson-Sabine E, Keville S, Murphy R, Robinson P, Winn S, Yi I: Do adolescents with eating disorder not otherwise specified or full-syndrome bulimia nervosa differ in clinical severity, comorbidity, risk factors, treatment outcome or cost? Int J Eat Disord 2008, 4I:498-504.

FI000 Factor 6.0 Must Read

Evaluated by Daniel le Grange 26 Aug 2008

29. Keel PK, Haedt A: Evidence-based psychosocial treatments for eating problems and eating disorders. J Clin Child Adolesc Psychol 2008, 37:39-61.

30. Schmidt U, Lee S, Beecham J, Perkins S, Treasure J, Yi I, Winn S, Robinson P, Murphy R, Keville S, Johnson-Sabine E, Jenkins M, Frost S, Dodge L, Berelowitz M, Eisler I: A randomized controlled trial of family therapy and cognitive behavior therapy guided selfcare for adolescents with bulimia nervosa and related disorders. Am J Psychiatry 2007, 164:59|-8.

FI000 Factor 6.4 Must Read

Evaluated by Howard Steiger 02 May 2007

31. Sysko R, Walsh BT: A critical evaluation of the efficacy of selfhelp interventions for the treatment of bulimia nervosa and binge-eating disorder. Int J Eat Disord 2008, 41:97-I I 2.

32. Robinson S, Perkins S, Bauer S, Hammond N, Treasure J, Schmidt U: Aftercare intervention through text messaging in the treatment of bulimia nervosa - feasibility pilot. Int J Eat Disord 2006, 39:633-8.

33. Schmidt $U$, Andiappan $M$, Grover $M$, Robinson S, Perkins $S$, Dugmore O, Treasure J, Landau S, Eisler I, Williams C: Randomised controlled trial of CD-ROM-based cognitive-behavioural selfcare for bulimia nervosa. Br J Psychiatry 2008, 193:493-500.

FI000 Factor 6.0 Must Read

Evaluated by Glenn Waller 27 Mar 2008

34. Strober M, Freeman R, Lampert C, Diamond J: The association of anxiety disorders and obsessive compulsive personality disorder with anorexia nervosa: evidence from a family study with discussion of nosological and neurological evidence. Int J Eat Disord 2007, 40:S46-S5I.

FI000 Factor 6.0 Must Read

Evaluated by Glenn Waller 27 Mar 2008

35. Treasure J, Smith G, Crane A: Skills-based Learning for Caring for a Loved One with an Eating Disorder. London, UK: Routledge; 2007. 